Check for updates

Cite this: J. Mater. Chem. A, 2018, 6, 23903

DOI: $10.1039 / c 8 \operatorname{ta} 90256 a$

www.rsc.org/MaterialsA

\section{Correction: Metal-based nanostructured materials for advanced lithium-sulfur batteries}

\author{
Juan Balach, (D) *a Julia Linnemann, (D) bc Tony Jaumann (D) ${ }^{\mathrm{b}}$ and Lars Giebeler (D) *b \\ Correction for 'Metal-based nanostructured materials for advanced lithium-sulfur batteries' by Juan Balach \\ et al., J. Mater. Chem. A, 2018, DOI: 10.1039/c8ta07220e.
}

The version of Fig. 4 in the published article is incorrect. The authors would like to replace Fig. 4 with the correct version, shown below.

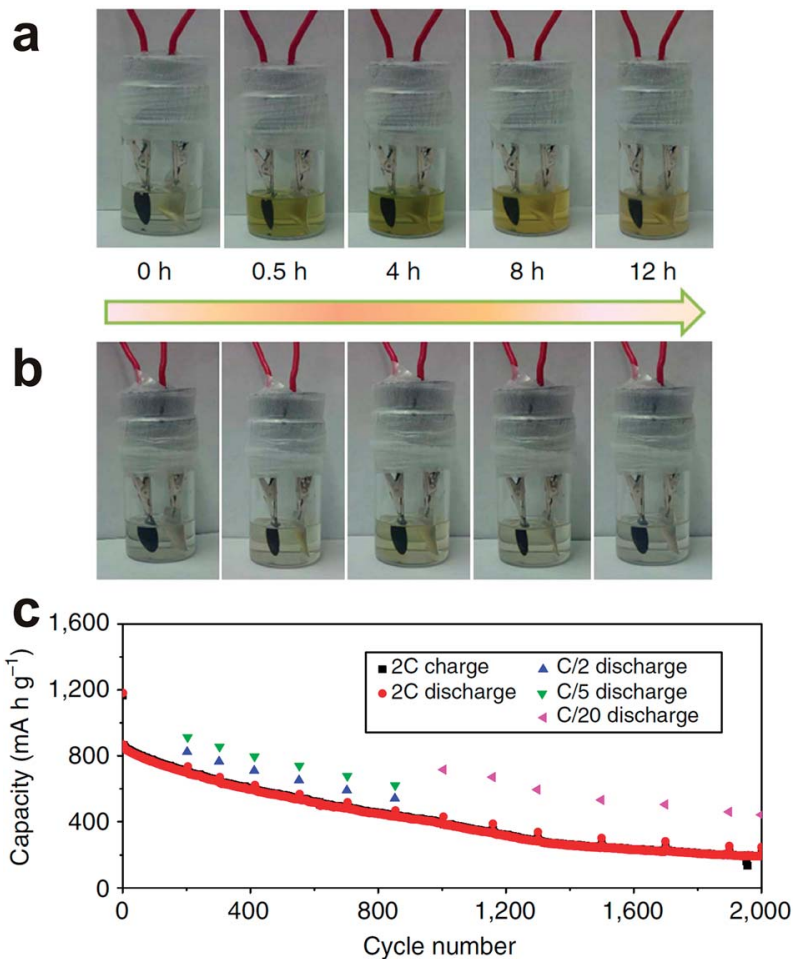

Fig. 4 Visual confirmation of LiPS trapping at different depths of discharge for (a) sulfur-Ketjen black and (b) sulfur- $\mathrm{MnO}_{2}$ cells. ${ }^{61}$ (c) Long-term cycling performance of the sulfur $-\mathrm{MnO}_{2}$ nanosheet composite cathode. ${ }^{61}$ (a-c) Reproduced with permission from ref. 61. Copyright 2015, Nature Publishing Group.

The Royal Society of Chemistry apologises for these errors and any consequent inconvenience to authors and readers. 